\title{
INCIDENCE OF POST-OPERATIVE ADR OF ANESTHETICS IN TERTIARY CARE TEACHING HOSPITAL: CLINICAL PHARMACIST PERSPECTIVES
}

\author{
ASHOK KUMAR M*, RAMYA A, SHANMUGASUNDARAM P \\ Department of Pharmacy Practice, School of Pharmaceutical Sciences, Vels Institute of Science Technology and Advanced Studies, \\ Pallavaram, Tamil Nadu, India. Email: ashokpharma06.sps@velsuniv.ac.in
}

Received: 10 October 2018, Revised and Accepted: 11 December 2018

\section{ABSTRACT}

Objective: The objective of the study was to evaluate the use of anesthetics in various general surgical conditions and to identify the adverse clinical outcomes of anesthetics in post-operative patients using questionnaire and verbal rating scale (VRS) score and to assess the treatment pattern of adverse clinical outcomes of anesthetics.

Methods: A prospective study was carried out in the Inpatient Department of General Surgery and ICU in S.R.M Medical College Hospital and Research Center involving patients up to 65 years of age. A total of 160 patients were recruited for the study based on inclusion and exclusion criteria. Patient demographics, medical history, type of surgery, type of anesthetics, duration of anesthesia, ASA Grade physical status, system examination, general examination, vital signs, and anesthetics drugs were assessed using pro forma. Adverse clinical outcomes of anesthetics were assessed using VRS score. Day of incidence of adverse outcomes was also monitored, and management of post-operative side effects and its effectiveness were assessed.

Results: During the study period, approximately 50\% of the patient's undergone general anesthetics reported post-operative pain. The incidence of post-operative nausea/vomiting, sore throat, and cough was highest in patient's undergone general anesthetics. The adverse outcomes were measured by VRS score, showed that mild adverse outcomes were predominated.

Conclusion: Patients who undergone general anesthetics developed high risk of adverse outcomes. The post-operative recovery of the patient was the main challenge. If an adverse drug reaction is not monitored the patients satisfaction can be weakened in general surgery. Hence, it is concluded that pharmacists can play a major role in assessing adverse clinical outcomes and its management.

Keywords: Anesthesia, General surgery, Post-operative, Verbal rating scale.

(C) 2018 The Authors. Published by Innovare Academic Sciences Pvt Ltd. This is an open access article under the CC BY license (http: //creativecommons. org/licenses/by/4. 0/) DOI: http://dx.doi.org/10.22159/ajpcr.2018.v11s4.31732

\section{INTRODUCTION}

An estimated 234 million surgical cases occur worldwide each year. The impact of this burden on individuals, health-care providers, and society as a whole is difficult to estimate, but there are data suggesting that in developed nations, surgical mortality may be between $0.4 \%$ and $0.8 \%$ and complications may occur in between $3 \%$ and $17 \%$ of patients. These data highlight post-operative morbidity and mortality as a major public health issue. As a result, development of strategies aimed at reducing post-operative morbidity and mortality is a major health challenge. Various interventions aimed at improving surgical outcomes [1].

Surgery induces important disturbances in body homeostases such as hypercatabolism, hypercoagulability, and inflammation, leading to a series of symptoms, and signs such as hypoxemia, pain, nausea, vomiting, ileus, sleep disturbances, and fatigue, and complications including pneumonia and myocardial infarction $[2,3]$ areas of the body treated by general surgery include the stomach, liver, intestines, appendix, breasts, thyroid gland, salivary glands, some arteries and veins, and the skin. The brain, heart, lungs, eyes, feet, kidneys, bladder, and reproductive organs, to name only a few are areas that require specialized surgical repaired in a standard surgical residency. However, post-operative symptoms such as pain and nausea have been reported to occur frequently in the immediate post-operative period [4-6].

Anesthesia facilitates a patient's ability to tolerate surgery and other procedures, and so it serves a vital function in health care. Anesthesia is provided by physicians, dentists, and nurse anesthetists and is essential for the over 26 million surgeries performed in the United States each year. The variation in anesthesia is due to the individual differences in patients and patient's preferences, the requirements of the surgery, the large selection of anesthetic agents to choose from, and the preference of the anesthesia provider.

\section{METHODS}

A prospective study was carried out in the Inpatient Department of General Surgery and ICU in S.R.M Medical College Hospital and Research Center involving patients up to 65 years of age. 160 patients were enrolled for the study based on inclusion and exclusion criteria. Patient demographics, medical history, type of surgery, type of anesthetics, duration of anesthesia, ASA Grade physical status, system examination, general examination, vital signs, and anesthetics drugs were assessed using pro forma. Adverse clinical outcomes of anesthetics were assessed using verbal rating scale (VRS) score. Day of incidence of adverse outcomes was also monitored, and management of post-operative side effects and its effectiveness were assessed.

\section{Ethical aspects}

The study was approved by the Institution Ethics Committee of the SRM Hospital. The investigators signed a commitment term related to data utilization for the study purposes, ensuring the ethical aspects, according to the resolution.

\section{RESULTS}

A total of 160 patients were recruited in the study. Post-operative questionnaire was successful in 150 patients. 15 patients were discarded from the study due to incomplete records. Thus, finally 135 samples were enrolled for the study. 
Type of surgery

Table 1 shows that Lap. appendectomy was found to be most common surgery done with $14 \%$ followed by hemorrhoidectomy (13\%) and split skin graft (12.\%).

\section{Type of anesthetics}

General anesthetics were found to be used more than spinal anesthetics. Table 2 shows that the percentage of general anesthetics used was $52 \%$ and spinal anesthetics used was $42 \%$.

Duration of anesthesia compared with the adverse outcomes Table 3 showed that the adverse outcomes were predominated in the duration of anesthesia $>1 \mathrm{~h}$. In the duration of anesthesia $<1 \mathrm{~h}$, pain occurred was found to be 15 , followed by vomiting, backache 4 , and headache were found to be 0 . In the duration of anesthesia $>1 \mathrm{~h}$, pain occurred was found to be 52 , followed by vomiting 18 , nausea 10 , and headache were found to be 6 .

Table 1: Distribution of type of surgery

\begin{tabular}{ll}
\hline Type of surgery & Frequency (\%) \\
\hline Lap. appendectomy & $19(14.1)$ \\
Mesh plasty & $15(11.1)$ \\
Open appendectomy & $16(11.9)$ \\
Total thyroidectomy & $9(6.7)$ \\
Split skin graft & $17(12.6)$ \\
Excisional biopsy & $8(5.9)$ \\
Open cholecystectomy & $11(8.1)$ \\
Lap. cholecystectomy & $3(2.2)$ \\
Hemorrhoidectomy & $18(13.3)$ \\
Lap. splenectomy & $5(3.7)$ \\
Hernioplasty & $4(3.0)$ \\
Amputation & $10(7.4)$ \\
Total & $135(100.0)$ \\
\hline
\end{tabular}

Table 2: Distribution of type of anesthetics

\begin{tabular}{ll}
\hline Type of anesthetics & Frequency (\%) \\
\hline General anesthetics & $70(51.9)$ \\
Spinal anesthetics & $65(48.1)$ \\
Total & $135(100.0)$ \\
\hline
\end{tabular}

Table 3: The duration of anesthesia compared with the adverse outcomes

\begin{tabular}{llll}
\hline Adverse outcomes & \multicolumn{2}{c}{ Duration of anesthesia } & Total \\
\cline { 2 - 3 } & $<\mathbf{~} \mathbf{h}$ & $\boldsymbol{> 1} \mathbf{h}$ & \\
\hline Head ache & 0 & 6 & 6 \\
Pain & 15 & 52 & 67 \\
Sore throat & 0 & 4 & 4 \\
Cough & 1 & 6 & 7 \\
Vomiting & 4 & 18 & 22 \\
Nausea & 2 & 10 & 12 \\
Backache & 4 & 7 & 11 \\
Fever & 1 & 5 & 6 \\
Total & 27 & 108 & 135 \\
\hline
\end{tabular}

Table 4: The distribution of ASA - grade in surgical patients

\begin{tabular}{ll}
\hline ASA grade & Frequency (\%) \\
\hline ASA-I (healthy patients) & $68(50.4)$ \\
ASA-II (mild systemic disease) & $64(47.4)$ \\
ASA-III (moderate systemic disease) & $3(2.2)$ \\
Total & $135(100.0)$ \\
\hline
\end{tabular}

Distribution of ASA - grade in surgical patients

The ASA-I healthy patients were found to be undergone general surgery more as compared to other ASA grades. The percentage distribution of ASA-I patients (healthy patients) was found to be $50 \%$ followed by ASA-II (mild systemic disease) 48\% and ASA-III (moderate systemic disease) $2 \%$ as shown in Table 4 .

Adverse outcomes of anesthetics in post-operative patients

Table 5 showed that among all the post-operative symptoms, pain $(50 \%)$ was found to be the most frequently reported symptom followed by vomiting (16\%) and nausea (9\%).

Table 5: The distribution of adverse outcomes of anesthetics in post-operative patients

\begin{tabular}{ll}
\hline Adverse outcomes & Frequency (\%) \\
\hline Headache & $6(4.4)$ \\
Pain & $67(49.6)$ \\
Sore throat & $4(3.0)$ \\
Cough & $7(5.2)$ \\
Vomiting & $22(16.3)$ \\
Nausea & $12(8.9)$ \\
Backache & $11(8.1)$ \\
Fever & $6(4.4)$ \\
Total & $135(100.0)$ \\
\hline
\end{tabular}

Table 6: Comparison between the type of anesthetics and adverse outcomes

\begin{tabular}{llll}
\hline $\begin{array}{l}\text { Adverse } \\
\text { outcomes }\end{array}$ & \multicolumn{2}{l}{ Type of anesthetics } & Total \\
\cline { 2 - 4 } & $\begin{array}{l}\text { General } \\
\text { anesthetics }\end{array}$ & $\begin{array}{l}\text { Spinal } \\
\text { anesthetics }\end{array}$ & \\
\hline Headache & 1 & 5 & 6 \\
Pain & 41 & 26 & 67 \\
Sore throat & 4 & 0 & 4 \\
Cough & 6 & 1 & 7 \\
Vomiting & 14 & 8 & 22 \\
Nausea & 9 & 3 & 12 \\
Backache & 1 & 10 & 11 \\
Fever & 6 & 0 & 6 \\
Total & 82 & 53 & 135 \\
\hline
\end{tabular}

Table 7: The day of incidence of adverse outcomes

\begin{tabular}{ll}
\hline Day of incidence & Frequency (\%) \\
\hline POD-I & $100(74.1)$ \\
POD-II & $31(23.0)$ \\
POD-III & $4(3.0)$ \\
Total & $135(100.0)$ \\
\hline
\end{tabular}

Table 8: The measurement of VRS score of adverse outcomes

\begin{tabular}{llllll}
\hline \multirow{2}{*}{ Adverse outcomes } & \multicolumn{2}{l}{ VRS-score } & \multicolumn{2}{c}{ Total } \\
\cline { 2 - 5 } & None & Mild & Moderate & Severe & \\
\hline Headache & 0 & 5 & 1 & 0 & 6 \\
Pain & 0 & 21 & 42 & 4 & 67 \\
Sore throat & 0 & 4 & 0 & 0 & 4 \\
Cough & 0 & 7 & 0 & 0 & 7 \\
Vomiting & 0 & 21 & 1 & 0 & 22 \\
Nausea & 0 & 12 & 0 & 0 & 12 \\
Backache & 0 & 10 & 1 & 0 & 11 \\
Fever & 0 & 6 & 0 & 0 & 6 \\
Total & 0 & 86 & 45 & 4 & 135 \\
\hline
\end{tabular}

VRS: Verbal rating scale 
Table 9: The treatment pattern of adverse outcomes of anesthetics in post-operative patients

\begin{tabular}{|c|c|c|c|c|c|c|c|}
\hline \multirow{2}{*}{$\begin{array}{l}\text { Adverse } \\
\text { outcomes }\end{array}$} & \multicolumn{7}{|c|}{ Treatment } \\
\hline & Nil & $\begin{array}{l}\text { Tramadol } \\
\text { (100 mgim) }\end{array}$ & $\begin{array}{l}\text { Diclofenac } \\
\text { (75 mg iv) }\end{array}$ & $\begin{array}{l}\text { Ondansetron } \\
\text { (4 mg iv) }\end{array}$ & $\begin{array}{l}\text { Paracetamol } \\
\text { (650 mg oral) }\end{array}$ & $\begin{array}{l}\text { Syp.Ascoril } \\
\text { (oral) }\end{array}$ & $\begin{array}{l}\text { Betadine } \\
\text { gargle }\end{array}$ \\
\hline Headache & 0 & 1 & 5 & 0 & 0 & 0 & 0 \\
\hline Pain & 0 & 46 & 21 & 0 & 0 & 0 & 0 \\
\hline Sore throat & 2 & 0 & 0 & 0 & 0 & 0 & 2 \\
\hline Cough & 2 & 0 & 0 & 0 & 0 & 5 & 0 \\
\hline Vomiting & 0 & 0 & 0 & 22 & 0 & 0 & 0 \\
\hline Nausea & 0 & 0 & 0 & 12 & 0 & 0 & 0 \\
\hline Backache & 0 & 1 & 10 & 0 & 0 & 0 & 0 \\
\hline Fever & 3 & 0 & 0 & 0 & 3 & 0 & 0 \\
\hline Total & 7 & 48 & 36 & 34 & 3 & 5 & 2 \\
\hline
\end{tabular}

Table 10: The effectiveness of therapy in post-operative patients

\begin{tabular}{llll}
\hline \multirow{2}{*}{ Adverse outcomes } & \multicolumn{2}{l}{ Effectiveness of therapy } & \multirow{2}{*}{ Total } \\
\cline { 2 - 3 } & Effective & Not effective & \\
\hline Headache & 6 & 0 & 6 \\
Pain & 48 & 19 & 67 \\
Sore throat & 4 & 0 & 4 \\
Cough & 7 & 0 & 7 \\
Vomiting & 22 & 0 & 22 \\
Nausea & 12 & 0 & 12 \\
Backache & 11 & 0 & 11 \\
Fever & 6 & 0 & 6 \\
\hline
\end{tabular}

Comparison between the type of anesthetics and adverse outcomes Table 6 shows that the incidence of adverse outcomes was found to be more with the use of general anesthetics. The patients suffering from pain in general anesthetics were found to be 41 followed by vomiting 14 and nausea 9 . The patients suffering from pain in spinal anesthetics were found to be 26 followed by backache 10 and vomiting 8 . The Chisquare value was found to be 26.594 which was statistically significant at $\mathrm{p}<0.001$.

\section{Day of incidence of adverse outcomes}

The adverse outcomes occurred were found to be more in the postoperative day 1 than the $2^{\text {nd }}$ and $3^{\text {rd }}$ day. The percentage distribution of adverse outcomes occurred in post-operative day 1 was found to be $74 \%$, whereas on post-operative day 2 it was found to be $23 \%$ and on post-operative day 3 it was found to be $3 \%$ as shown in Table 7 .

\section{Measurement of VRS score of adverse outcomes}

The adverse outcomes of anesthesia were measured by VRS score. Table 8 shows that mild headache was found in 5 patients and moderate headache in 1 patient. Moderate pain was found to be more in 42 patients followed by mild in 21 patients, and severe pain was found in 4 patients. In the case of vomiting, mild was found in 21 patients and moderate was found in only 1 patient. Mild backache was found in 10 patients, moderate backache was found in 1 patient, and mild fever was found in 6 patients. Chi-square value was found to be 61.087 which was statistically significant at $\mathrm{p}<0.001$.

Treatment pattern of adverse outcomes of anesthetics in postoperative patients

In the study, it was observed that injection diclofenac $75 \mathrm{mg}$ was found to be prescribed more for pain followed by backache and headache. Injection tramadol $100 \mathrm{mg}$ was found to be prescribed more for pain followed by headache and backache. Injection ondansetron was found to be prescribed more for vomiting followed by nausea as shown in Table 9 .

\section{Effectiveness of therapy in post-operative patients}

The treatment was found to be effective for 116 patients. 19 patients who suffered from pain reported that the treatment was not as effective as shown in Table 10.

\section{DISCUSSION}

The role of adverse clinical outcomes of anesthetics after general surgery is often underestimated $[7,8]$. Compared to other perioperative complications it might seem to be of minor importance. It rarely kills the patient and almost never becomes chronic. However, it is a very unpleasant experience for patients. All of these results in prolonged ICU stay, delayed discharge from the hospital and, last but not least, have an economic impact. Hence, it is more urgent necessity to minimize the occurrence of adverse clinical outcomes of anesthetics after surgery so that the patients could be discharged early after surgery [9].

The progress of the post-operative recovery process remains to be studied from a patient perspective. The patient reported questionnaire addressed in this study could be useful to study adverse clinical outcomes of anesthetics after general surgery $[10,11]$. This improves their understanding about the adverse clinical outcomes and importance of medication decreased the morbidity rate.

The development of adverse outcomes postoperatively is influenced by many factors-type of patients, type of anesthetics, duration of anesthesia, etc. Nausea, vomiting, pain, headache, backache, sore throat, cough, and fever were found to be common among the more frequent minor squeal that occurred after general surgery [12].

The type of anesthetics was found to play a role in determining the adverse outcomes. Approximately $50 \%$ of the patients undergoing general anesthetics reported post-operative pain. The incidence of post-operative nausea/vomiting, sore throat, and cough was found to be high in patients undergoing general anesthetics. The incidence of backache and headache was highest in local anesthetics patients followed by spinal anesthesia $[13,14]$.

The adverse outcomes were measured by VRS score which showed that mild adverse outcomes were predominated. Optimal management was given to patients and was found to be effective. Similar results were found in the study conducted by Guillermo et al. who reported that predicting the post-operative grade of the patient in the $1^{\text {st }} \mathrm{h}$ after surgery was effective in the faster recovery of patients.

\section{CONCLUSION}

In this study, postoperatively pain, nausea and vomiting, headache, cough, fever, backache, and sore throat were found to be the most frequent adverse outcomes of anesthetics in general surgery. Patients undergone general anesthetics were at developed high risk of adverse outcomes. The lowest complication was associated with local anesthetics. The post-operative recovery of the patient is the main challenge. If it is not monitored the patient's satisfaction can be diminished in general surgery. These studies may improve anesthetic care and will assist in the development of new treatment strategies for improving adverse outcomes. Hence, it is concluded that pharmacists can play a major role in assessing adverse clinical outcomes and its management. 


\section{CONFLICTS OF INTEREST}

All authors have none to declare.

\section{REFERENCES}

1. Aitkenhead AR. Injuries associated with anaesthesia. A global perspective. Br J Anaesth 2005;95:95-109.

2. Kehlet H, Willmore DW. Multimodal strategies to improvesurgical outcome. Am J Surg 2002;183:630-44.

3. Kehlet H, Dahl JB. Anaesthesia, surgery, and challenges in postoperativerecovery. Lancet 2003;362:1921-8.

4. Fischer SP., Bader AM. Generalanaesthesia versus general anaesthesia for abdominal aorticintensity and risk factors. Anest Analg 2009; $101: 1643-50$

5. Fox AJ, Rowbotham DJ. Anaesthesia. BMJ 1999;319:557-60.

6. Amponsah G. Postoperative nausea and vomiting in Korle Bu teaching hospital. Ghana Med J 2007;41:181-5.
7. Guillermo A, Vinoles J, Ibanez MV. Predicting recovery at home after ambulatory surgery. BMC Health Serv Res 2011;111:269.

8. Swan BA, Maislin G, Traber KB. Symptom distress and functionalstatus changes during the first seven days after ambulatorysurgery. Anesth Analg 1998;86:739-45.

9. Bennett P N, Brown M J. Anaesthesia and Neuromuscular Block. Clinical Pharmacology $9^{\text {th }}$ ed. New York: Churchil Livingstone; 2003. p. 355-7.

10. Bonnet F, Marret E. Influence of anaesthetic and analgesic techniques on outcome after surgery. Br J Anaesth 2005;95:52-8.

11. Boogaerts JG, Vanacker E, Seidel L, Albert A, Bardiau FM. Assessment of postoperative nausea using a visual analogue scale. Acta Anaesthesiol Scand 2000;44:470-4.

12. Miller BD. Spinal, Epidural, Caudal Anesthesia, Miller, Anesthesia. $7^{\text {th }}$ ed. Philadelphia, PA: Churchill Livingstone; 2010. p. 1611-38.

13. Casey WF. Spinalanaesthesia a practical guide. Update Anaesth 2000;12:22-7.

14. Chung F, Ritchie E, Su J. Postoperative pain in ambulatorysurgery. Anaesth Anal 1997;85:808-16. 